\title{
SWASH ZONE BED LEVEL CHANGES AND SEDIMENT ENTRAINMENT AT THE SURF- SWASH BOUNDARY
}

\author{
Stine G. Jensen ${ }^{1}$, Troels Aagaard ${ }^{1}$ and Tom. E. Baldock ${ }^{2}$
}

\begin{abstract}
In the process of estimating the effect of sediment advection into the swash zone from bore collapse, a method in which buried self-logging pressure transducers are used to measure bed level changes in the swash zone, over a timeframe of several hours to inter-swash level, has been tested against bed level changes obtained from rod measurements. The test shows perfect agreement in the upper and mid swash while minor disagreement $(1 \mathrm{~cm})$ in the lower swash occurred. The deployment of self-logging pressure transducers has proven to be an accurate, easy and flexible method to obtain highly detailed data on water levels and bed elevations in the swash zone. Water levels derived from the pressure transducers show that swash zone characteristics vary from the upper to lower swash. Using pressure transducers in the swash zone coupled with measurements of the hydrodynamics and sediment concentrations at the outer boundary of the swash zone will improve the ability to explain the role of sediment advection from bore collapse. In relation to this, a method which consistently identify bores at the surf-swash boundary and quantifies the suspended sediment load carried by such bores prior to their collapse and run-up in the swash zone, is also presented.
\end{abstract}

Keywords: swash zone characteristics; bed level changes; bores at the surf-swash boundary

\section{INTRODUCTION}

As a result of being at the transition zone between sea and land, the hydrodynamics governing the morphological development in the swash zone are very important. This has been widely recognised and various studies have emphasised this (see reviews of e.g. Butt and Russell, 2000; Brocchini and Baldock, 2008). Instrumentation for measurements in the swash zone have improved and therefore increased the attention on swash zone hydrodynamics and sediment transport.

The swash zone is ideally defined as that part of the foreshore which is alternately wet and dry with a shoreline motion at the same frequency as the incident waves. However, the position of the shoreline is not only dependant on the incident waves, but also on infragravity waves and tide which complicates the definition of the swash zone because the position of the shoreline varies a lot. The varying extension of the swash zone and the changing hydrodynamics from the upper to lower swash makes the swash zone a very dynamic environment where large hydrodynamic and morphological changes can happen fast. It is therefore a quite complicated task to model the hydrodynamics governing the morphological development in the swash zone. Furthermore, fieldwork on the hydrodynamics in the swash zone has been limited by the instrumentation as the instruments have been too large relative to the water depth, creating problems with bubbles and foam and obtaining data from small water depths. The need for smaller instruments have partly been met, e.g. through the development of mini OBS sensors (optical backscatter), FOBS sensors (fibreoptical backscatter) and micro ADVs (Acoustic Doppler Velocimeter), but as these instruments are mainly designed for laboratory experiments they are more fragile. This causes problems under the high energy conditions that often exist in the field. What is needed, are robust instruments, preferable self-logging, which are easy to deploy and move concurrent with the swash zone as it moves with the rising or falling tide.

Field observations in the swash zone show that suspended sediment concentrations are often larger in the uprush than in the backwash. For some time focus has been on modelling sediment transport in the swash zone using Bagnold-type energistics models for bedload (e.g. Hughes et al., 1997a; Masselink and Hughes, 1998; Puleo et al., 2000). In general, mixed results have been obtained and several explanations for this have been put forward including that of sediment advection from the point of bore collapse (Hughes et al., 1997b; Pritchard and Hogg, 2005; Aagaard and Hughes, 2006; Hughes, Aagaard and Baldock, 2007). The point of bore collapse defines the boundary between the inner surf zone and the swash zone and occurs when an inner surf bore breaks for the last time as it approaches the shore. Being able to quantify the sediment advection from collapsing bores will improve the understanding of swash zone morphodynamics and ultimately improve existing models for swash zone sediment transport. In order to do this collapsing bores have to be identified and the amount of sediment entrained at the bore front quantified. Then, how far this sediment is transported landward

\footnotetext{
${ }^{1}$ Department of Geography and Geology, University of Copenhagen, Øster Voldgade 10, DK-1350 Copenhagen K, Denmark.

${ }^{2}$ School of Civil Engineering, The University of Queensland, St Lucia, Brisbane, QLD, 4072, Australia.
} 
and which effect it has on the swash zone morphology has to be estimated. This requires measurements in the swash zone on a wave-by-wave basis. Baldock et al. (2005) have presented a method to determine bed level changes on a wave-by-wave basis in the swash zone using self-logging buried pressure transducers (PTs). The method determines the water level and the net accretion or erosion at a given point. Swash events and their effect on the bed level can be tracked throughout the swash zone if a cross-shore array of PTs closely spaced is deployed. If accretion events in the swash zone consistently coincide with large sediment suspension events from bore collapse, this is a good indication that sediment advection from bore collapse is an important process in swash zone morphodynamics.

This paper tests the method presented by Baldock et al. (2005) in which buried self-logging PTs are used to obtain bed level changes in the swash zone using measurements at inter-swash frequencies over a duration of several hours. These changes can be used to calculate very detailed sediment volume changes on the foreshore. Furthermore, examples of swash events derived from the PTs in the upper, mid and lower swash are presented. As stated above, using PTs in the swash zone coupled with measurements on the hydrodynamics and sediment concentrations at the outer boundary of the swash zone can potentially help to explain the role of sediment advection from bore collapse. In relation to this a method which consistently identify bores at the surf-swash boundary and quantify the suspended sediment load carried by such bores prior to their collapse and run-up in the swash zone, is presented in the paper as well.

\section{METHODOLOGY}

\section{Field site}

The data presented in this study, were collected during a field campaign in November 2007 at Vejers beach located on the west coast of Denmark which is exposed to the North Sea (Figure 1).

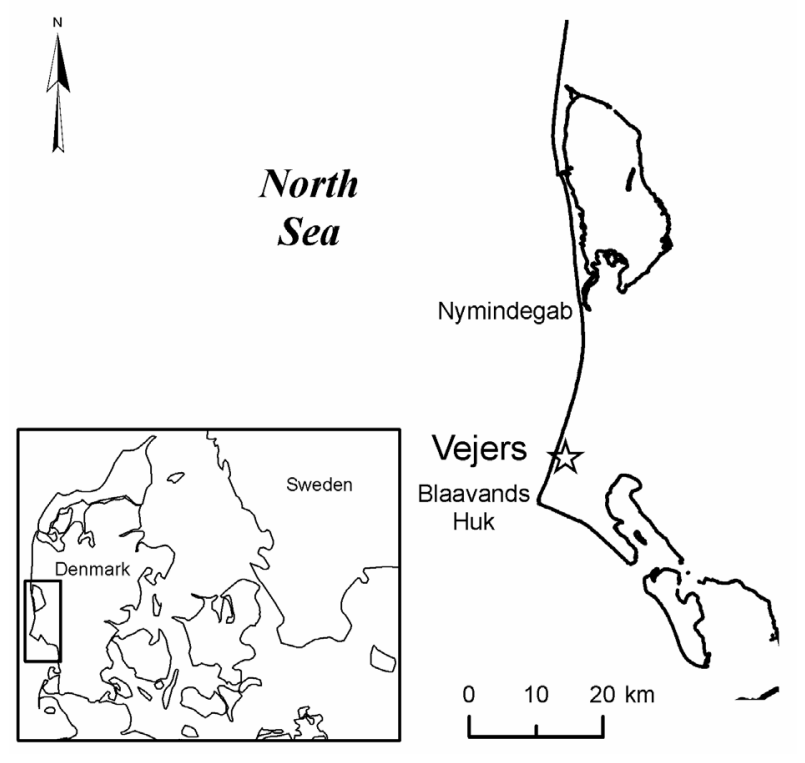

Figure 1. Sketch map showing the location of Vejers (marked with a star) on the west coast of Denmark.

Tides at Vejers are semidiurnal, with spring and neap tidal ranges of approximately 1.2 and $0.6 \mathrm{~m}$, respectively. The southerly directed net littoral drift is about $2.3 \times 10^{6} \mathrm{~m}^{3} \mathrm{yr}^{-1}$ some $15 \mathrm{~km}$ north of Vejers and decreases to about zero $8 \mathrm{~km}$ further south of Vejers (KDI, 2001). This large gradient in the littoral drift facilitates the accretion (the rate of shoreline advance is about $1 \mathrm{~m} / \mathrm{yr}$ ) that takes place at Vejers, where the subaerial beach is approximately $150 \mathrm{~m}$ wide and backed by $8-10 \mathrm{~m}$ high vegetated foredunes. The foreshore has a mean slope of $\beta \sim 0.026$ and a mean grain size of $230 \mu \mathrm{m}$.

The mean annual offshore significant wave height $\left(H_{s}\right)$ is $1.2 \mathrm{~m}$ and the maximum annual offshore wave height $H_{s}$ is about $6.5 \mathrm{~m}$. A multiple bar-system of 3-4 nearshore bars exists. At all times, waves tend to break by plunging across the seaward slopes of the bars and reform in the troughs. The beach state is modally intermediate (Wright and Short, 1984) 


\section{Methods and instrumentation}

Two methods to record morphological and sediment volume changes on the foreshore were used. Twenty-seven $5 \mathrm{~mm}$ diameter steel rods with a spacing of $2 \mathrm{~m}$ were placed in a cross-shore transect (Figure 2).

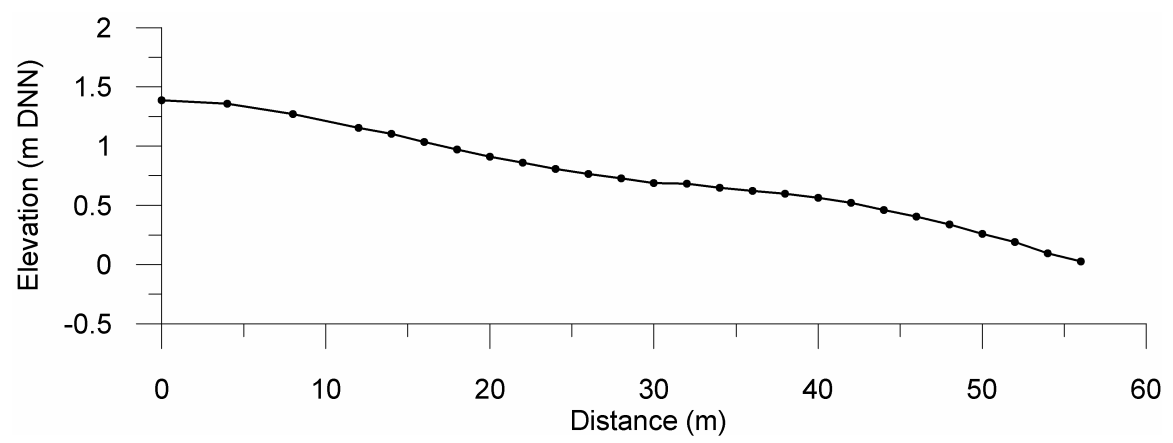

Figure 2. Profile of the foreshore and the location of rods (marked with dots).

In order to estimate the net accretion or erosion across the transect, volumetric changes were recorded as $\mathrm{m}^{3}$ per meter width of the beach under the assumption that elevation changes at each rod represented bed elevation changes within one square meter. For morphology with almost linear slopes this is a reasonable assumption. The rods were measured daily during low tide and every half hour over a full tidal cycle on certain days when wave conditions were expected to lead to significant profile adjustment. All rod measurements were referenced to a benchmark (DNN, the Danish Ordnance Datum, approximately corresponding to mean sea level) in the dunes using a Nikon Total Station.

Furthermore, sediment volume changes on the foreshore were recorded using pressure transducers which were buried 5-10 cm below the sand surface in the swash zone. This method can be used to measure bed elevation changes over a time frame of several hours or inter-swash changes using the method developed by Baldock et al. (2005) and further discussed by Brocchini and Baldock (2008). As the flow depth falls to zero, the signal recorded by the transducer is equal to the elevation of the water table and hence the elevation of the sand above the transducer, provided that the sand is close to fully saturated at that time. Immediately after the backwash on a medium to fine sand beach this is usually the case. An algorithm extracts the bed elevation and swash depths from the measured record. However, it should be noted that the technique relies on the water depth reducing to zero at the measurement location which is not always the case, and care is needed to avoid misleading results from slowly draining thin water films of water. Consequently, measurements should be supported by manual rod measurements around the inner surf-swash zone boundary. For this field experiment, a cross-shore array of nine INW PT2X self-logging PTs, located with varying spacing, was deployed across the inner surf and swash zone. The PTs were moved concurrent with the swash zone as it translated onshore or offshore with the rising or falling tide. Each transducer was buried approximately $0.5 \mathrm{~m}$ north of one of the bed elevation rods to form a rod-transducer pair at the same cross-shore location. The PTs were synchronised and logged at $4 \mathrm{~Hz}$ during each rod measurement period.

At the surf-swash boundary, data on water levels was obtained using a pressure transducer (Druck Model PTX1830), fluid velocities using an Acoustic Doppler Velocimeter (ADV, Sontek 10MHz) and sediment concentrations using three D\&A Instruments optical backscatter sensors (OBS) at different elevations. All instruments were synchronised and logged at $16 \mathrm{~Hz}$ during each record (34 min).

\section{Data analysis}

Traditionally, the term swash has been used to describe both the shoreline motion and the hydrodynamics of the water body moving up and down the foreshore. Several studies show that the hydrodynamics, and hence sediment transport, differs between the "lower" and "upper swash" (Aagaard and Hughes, 2006; Weir et al., 2006; Jensen et al., 2009). The lower swash is influenced by wave-swash interaction while the upper swash is only influenced by pure swash motion. How to distinguish between these two regions within the swash zone is perhaps straightforward in the outer extremes but less in the transition between the two. It therefore seems sensible to operate with the term "mid swash" following Aagaard and Hughes (2006). As the hydrodynamics differ throughout the swash zone it is therefore necessary to estimate which part of the swash zone is represented in data collected here. Previous studies (Masselink et al., 2005; Aagaard and Hughes, 2006) have determined 
the percentage of time that the bed at the instrument position was inundated to indicate the approximate position in the swash zone. To estimate the inundation time Aagaard and Hughes (2006) used the time the ADV was immersed to indicate the position in the swash zone. The longer immersion time, the closer to the seaward boundary of the swash zone and vice versa. In this study, more accurate inundation times can be obtained because the pressure traducers were located below the bed level, thus recording water levels at all times. Using the ADV will underestimate the actual inundation time and theoretically displace the positions of the upper, mid and lower swash zones. The procedure for distinguishing between upper, mid and lower swash presented by Aagaard and Hughes (2006) has been used here regarding the percentages but instead of immersion time of ADV, inundation of pressure transducer has been used. I.e. the upper swash is defined as the PT being inundated $1-40 \%$ of the time, mid swash as $40-75 \%$, lower swash as $75-95 \%$ and inner surf as $95-100 \%$. These boundaries should not be interpreted as rigid though, because some transition between upper swash, mid swash, lower swash and inner surf conditions will always occur.

Extraction of bed levels from the PT time series was performed under the assumption that the bed emerges at least once every minute, and a 1-min moving window, moving one time step at a time, was therefore used to find the minimum bed levels. The PT output had to be stable for at least $1.5 \mathrm{~s}$ to qualify as bed level otherwise it would be discarded and categorised as water level. This method is similar to that used by Masselink et al. (2009), but in the present study a 2-min moving window was furthermore applied in the mid and lower swash because the incidents of swash-wave interactions seemed to appear in groups resulting in the bed level only being exposed about every 100 seconds. This corresponds to the infragravity wave period observed and the effects of shoreline motion at infragravity scale are in this way taken into account using this method.

In order to identify the point of bore collapse and to identify swash events a method has been developed which selects the bores from a bore front steepness criterion on a wave-by-wave basis. The reason for developing this method has been that a steepness criterion appeared to describe the bores in the inner surf and swash zone better than using zero crossing analysis. Using zero crossing analysis in the inner surf and swash causes some problems because the water level varies a lot in this zone, and the method is very sensitive to the definition of the mean water level around which the zero crossings are defined. Power et al. (2010) have demonstrated how the use of zero crossing analysis can lead to misinterpretation of wave heights and the shape of the waves. When using the steepness criterion however, it is possible to exclude undulations on the water surface which are caused by turbulence while still identifying all the bores. No filtering, apart from a filter to remove instrument noise, is used.

Once individual bores have been identified, sediment loads can be calculated e.g. as total instantaneous or total maximum loads $\left(C_{\max }\right)$. Total instantaneous loads are calculated as the sum of the sediment load from all OBS sensors integrated over the water depth $(h)$. Because of the finite time it takes to lift sediment grains, the maximum load does not occur simultaneously up through the water column. Under the assumption that the maximum sediment load occurs shortly after the bore front has passed, and that we are only interested in sediment suspended by the bore, the maximum sediment load from a bore is defined as the maximum total instantaneous load within $2 \mathrm{~s}$ after the bore front has passed, integrated over the water depth:

$$
C_{\max }=\left(\sum_{h_{\text {bottom }}}^{h_{\text {top }}} c(z) \Delta z\right)_{\text {max }, 2 s}
$$

where $c(z)$ is the sediment concentration at OBS sensor level $z, \Delta z$ is the height of the water column represented by that OBS sensor and max,2s denotes the maximum total instantaneous sediment concentration within $2 \mathrm{~s}$ after the bore front has passed.

\section{RESULTS}

\section{Bed levels}

An example time series of $3 \frac{1 / 2}{h}$ from one of the PTs (located at $38 \mathrm{~m}$ in the profile, see Figure 2) and the corresponding rod is shown in Figure 3. 


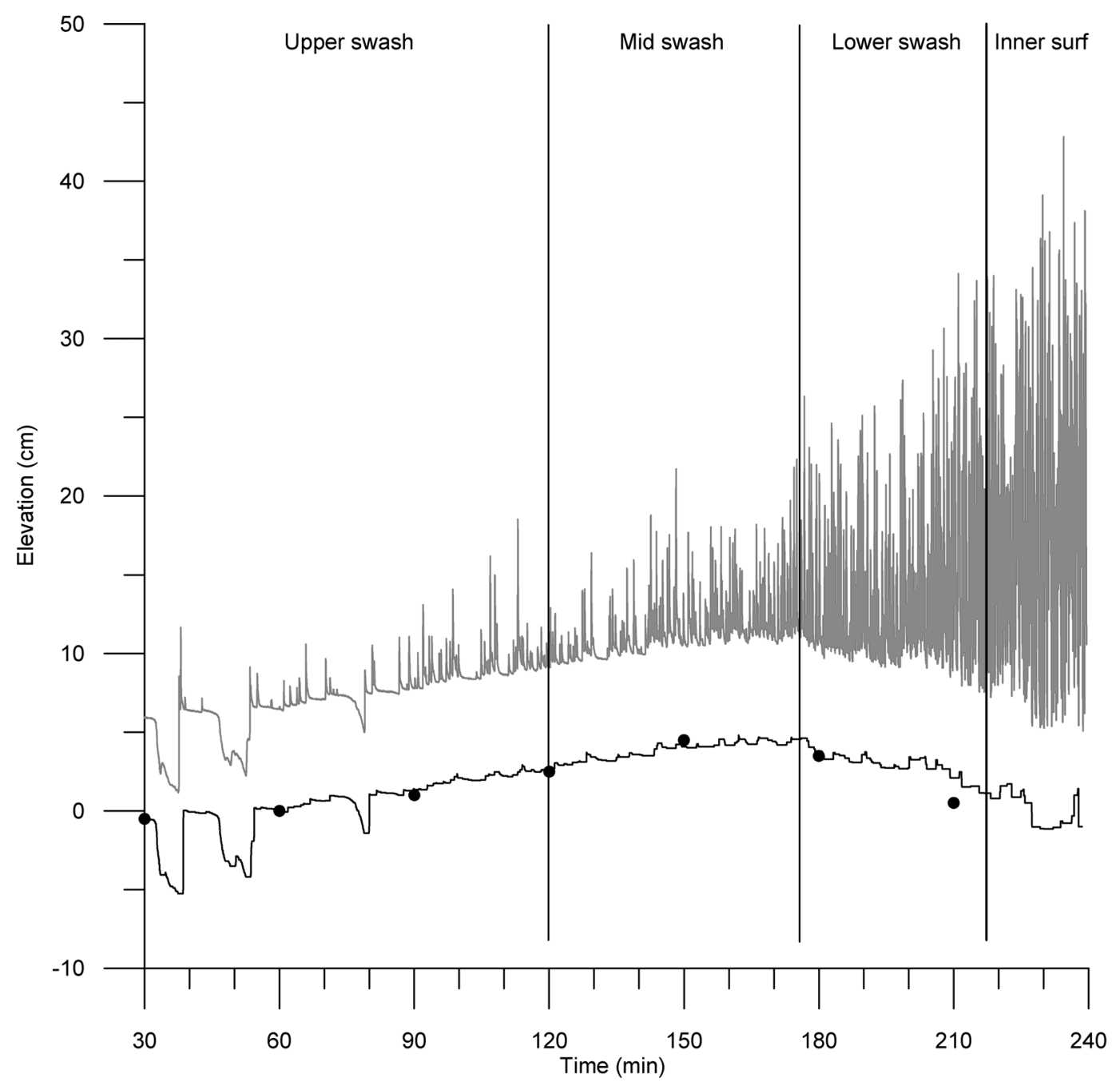

Figure 3. Example time series of data derived from PT located at $38 \mathrm{~m}$ in the foreshore profile. Relative water level (grey solid line), relative bed level (black solid line) and relative bed level derived from rod measurements (black dots).

The three drops (from 30-90 minutes) in the output signal from the PT, and therefore also in the derived relative bed level, indicate that the transducer is located in the upper-most swash. These kinds of drops develop as the water is percolating into the bed and the sand above the PT becomes unsaturated. The drop events indicate that it takes some time for the bed to become unsaturated because the drops occur some time (up to minutes) after a swash event has passed. This supports the assumption made for applying the PTs in the swash zone that on a medium to fine sand beach, the sand is fully saturated immediately after the backwash. As soon as the PT is inundated the PT output signal jumps back to the correct free surface pressure which indicates that this method to estimate bed level changes is reliable even though some infiltration occurs. Comparing bed levels derived from the rod and PT shows good agreement with accretion during the first two hours followed by erosion. Comparing the total bed level changes during the first $2 \frac{1}{2} \mathrm{~h}$, which corresponds to upper to mid swash conditions, using the two methods gives a perfect match of $0.04 \mathrm{~m}$. When comparing the relative bed levels in the lower swash minor disagreement occurs. During the period 180-210 minutes the rod measurements estimated a bed level change of $-0.03 \mathrm{~m}$ and the PT $-0.02 \mathrm{~m}$.

Figure 4 displays example PT time series from the upper, mid and lower swash. 
(a)
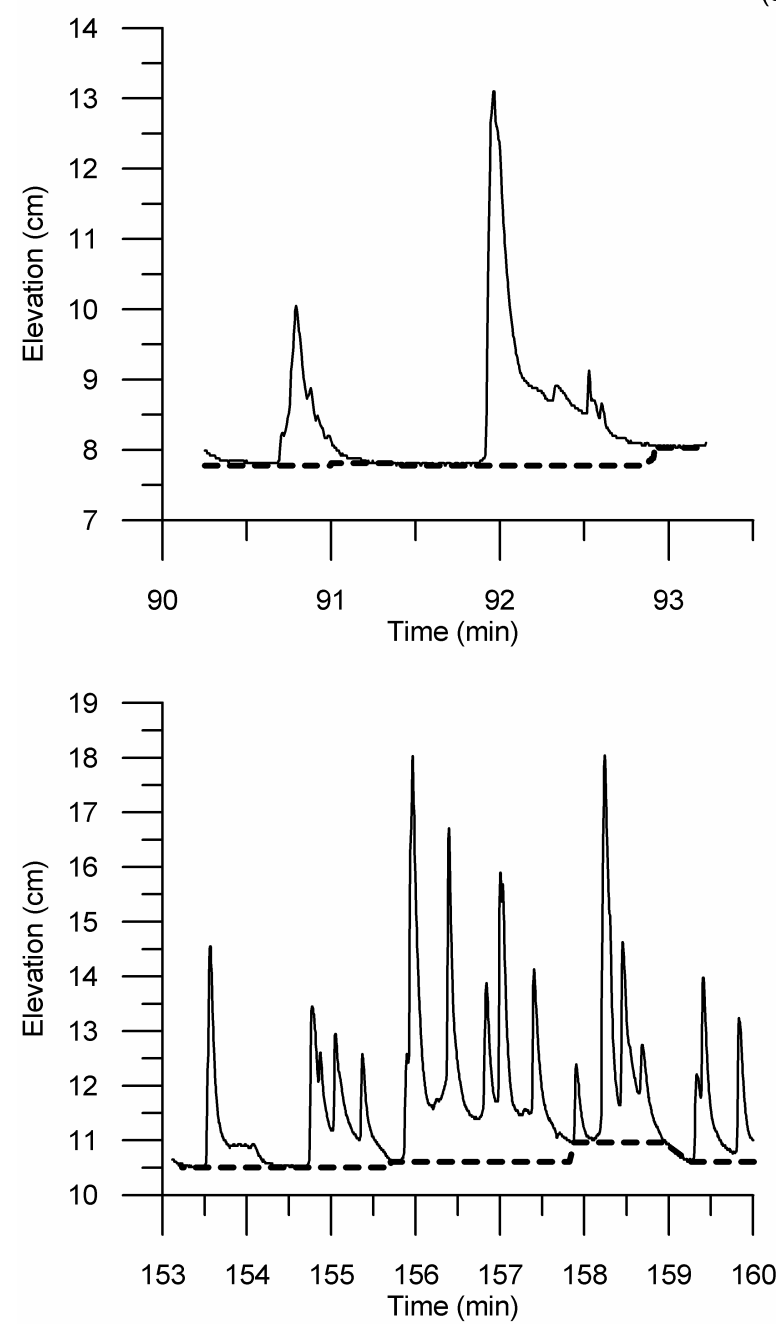

(b)

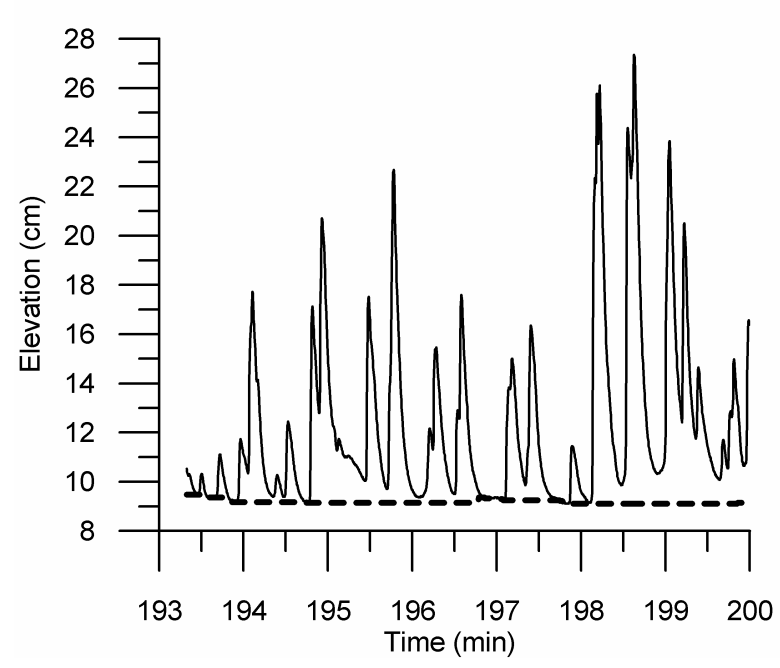

Figure 4. Example time series from (a) upper swash, (b) mid swash and (c) lower swash, all derived from a PT. Relative water level (solid line) and relative bed level (dashed line).

From the upper to lower swash, swash events become more frequent and swash-wave interaction more prevalent. The example from the upper swash illustrates that bed level changes, in this case of about 2 $\mathrm{mm}$, can be obtained at inter-swash level using the PTs. It also shows that while one swash event does not result in bed level change the succeeding larger event does. In the example from the mid swash the 
groupiness of the swash-wave interaction events mentioned before can be observed and the bed level is identified between these groups. In the example from the lower swash the groups of swash-wave interaction events are different from those in the mid swash. The events in the lower swash are in general larger and where the interactions in the mid swash is probably dominated by swash being overrunned by swash bores (defined as wave capture by Hughes and Moseley (2007)), wave-backwash interaction is likely to dominate the lower swash, thus changing the shape of the groups.

Large bed elevation changes from individual swash events have been observed using the PTs. Figure 5 displays examples of an accreting and an eroding event.

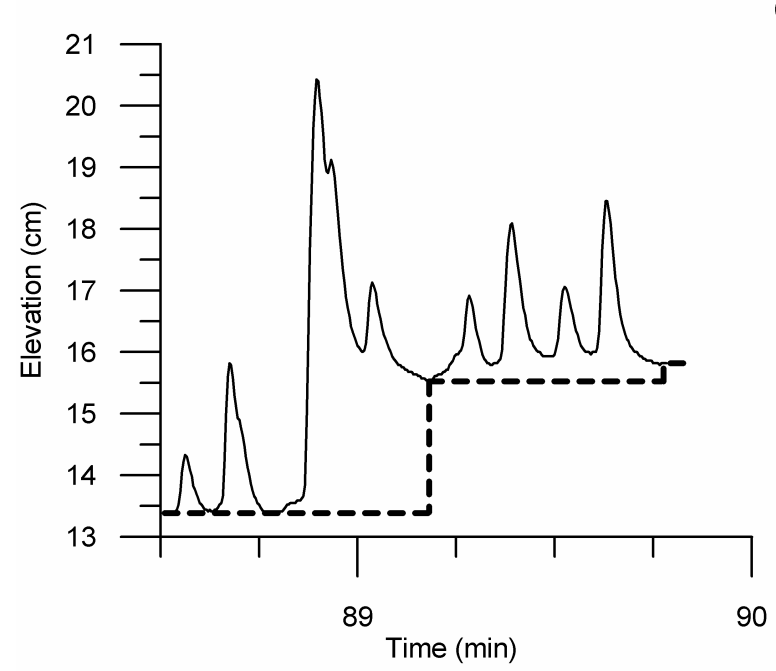

(a)

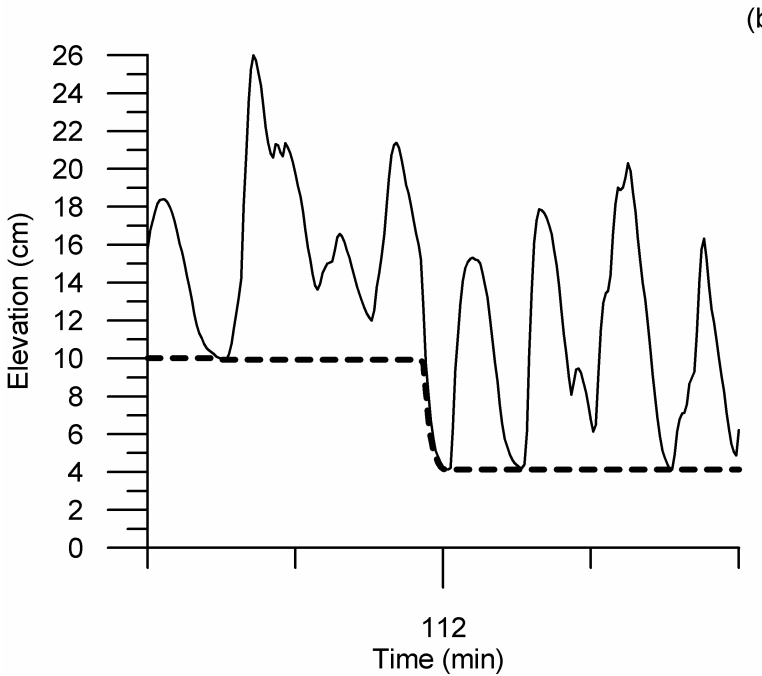

Figure 5. Examples of (a) accreting event and (b) eroding event, derived from a PT. Relative water level (solid line) and relative bed level (dashed line).

The accreting event occurs in the mid swash and cause a bed level change of about $+2 \mathrm{~cm}$. The eroding event occurs in the lower swash and cause a bed level change of about $-6 \mathrm{~cm}$. In both events the bed elevation change found could be the result of bedforms migrating landward (Baldock, 2009). Even though it seems that large bed elevation changes may occur as a result of a single swash event, it has to be stressed, that especially in the lower swash, bed elevation changes tend to be overestimated. The choice of window size to find the bed level highly influences the bed elevation changes found. Figure 6 displays the difference between using a $1 \mathrm{~min}$ and a 2 min moving window in the mid swash. 
(a)

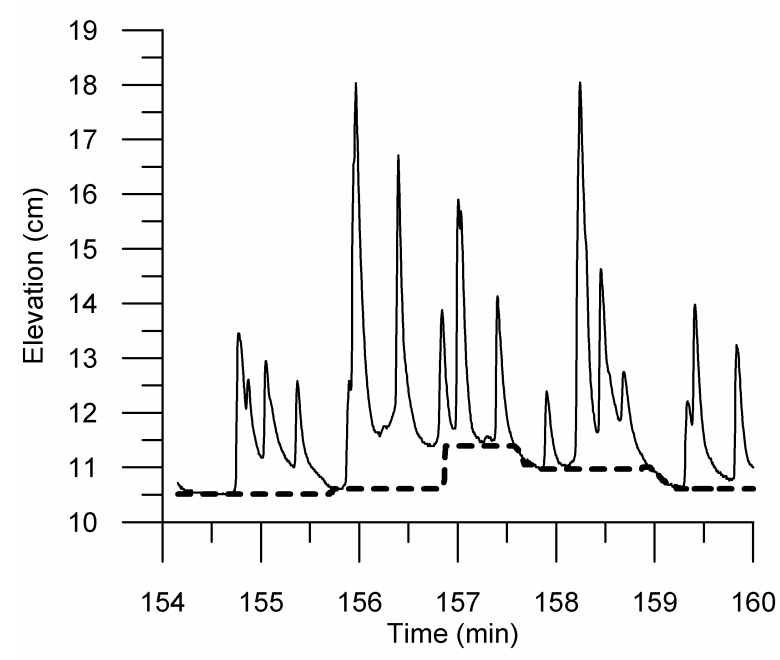

(b)

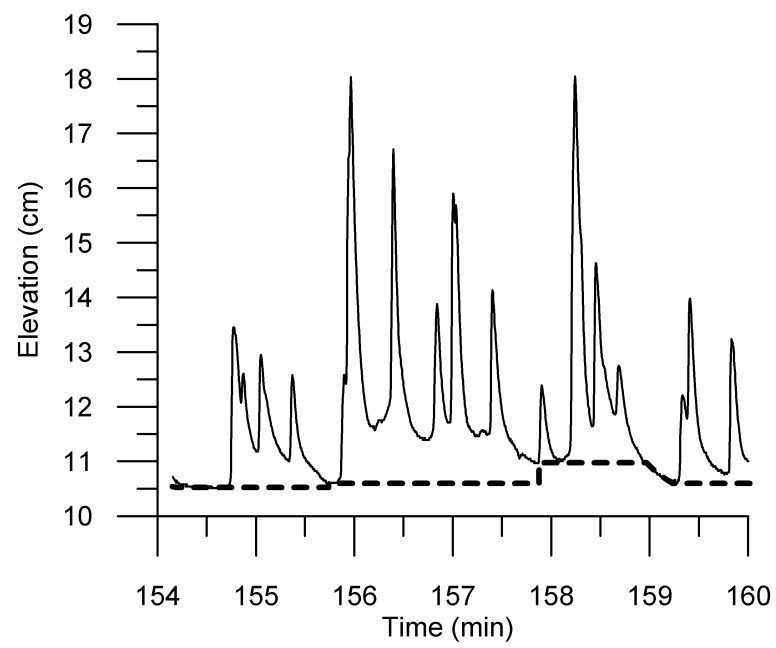

Figure 6. Examples of the use of (a) 1 minute window and (b) 2 minute window to extract bed levels from PT data in the mid swash. Relative water level (solid line) and relative bed level (dashed line).

Choosing a 1 min window a bed elevation change of about $8 \mathrm{~mm}$ is found whereas if a 2 min window is chosen no bed elevation change is found for the same event. Looking at the corresponding water level it is clear that the bed level found using a 1 min window is overestimated, as it in fact represents the water level at a swash bore front overrunning the previous swash event.

\section{Identifying bores}

In order to relate bed level changes found using the PTs to swash events and sediment advection from collapsing bores, individual bores have been defined by the identification of troughs and peaks in the data on water level. An example is displayed in Figure 7, upper panel. 


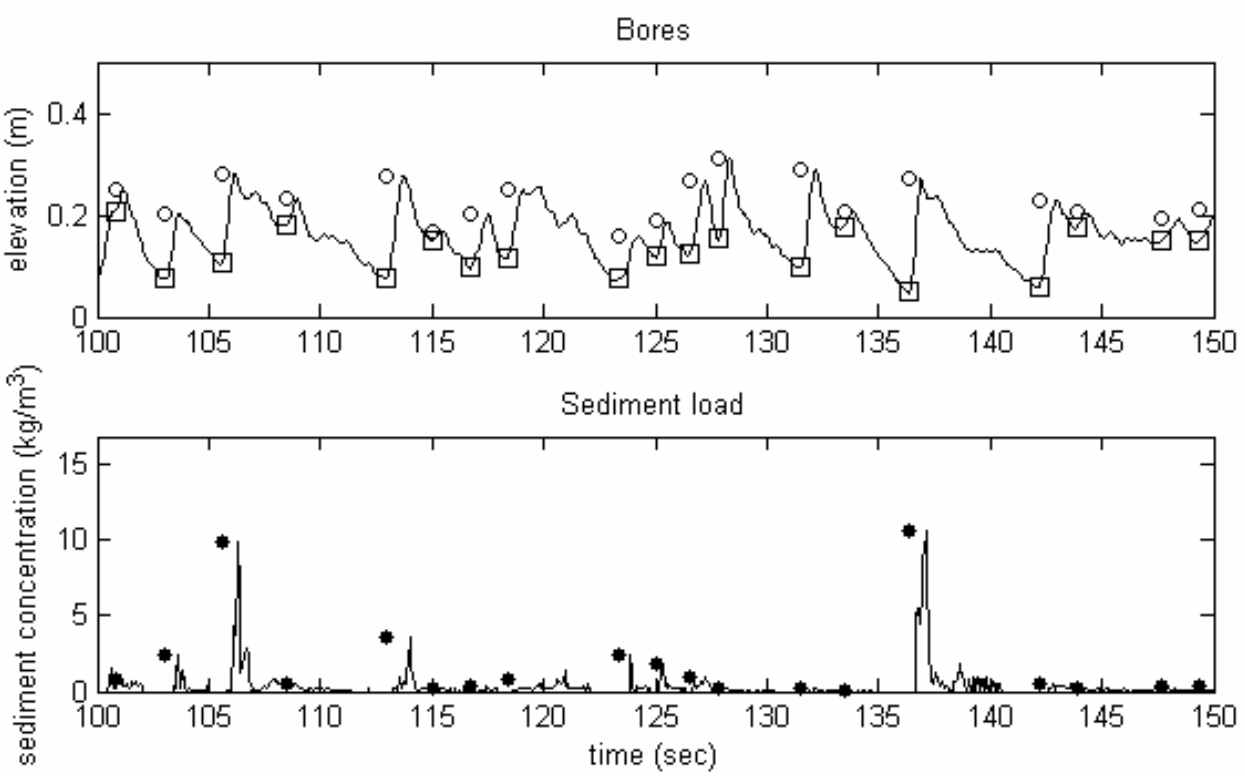

Figure 7. Identification of bores and corresponding maximum sediment loads at the bore front at the surfswash boundary. Upper panel: water level (solid line), troughs (squares), peaks (circles). Lower panel: total instantaneous sediment load (solid line), total maximum sediment loads under defined bores (black dots).

The total instantaneous sediment load and the total maximum sediment load under the defined bores have been derived as well, Figure 7, lower panel. As it can be observed, the maximum sediment concentrations occur just after the bore front has passed. The example is from the surf-swash boundary and is therefore dominated by wave-swash interaction. When using the method to identify bores presented here it is also possible to extract information on bore heights and water levels.

\section{DISCUSSION}

Bed elevation changes have been quantified using rods and PTs. The method of using rods is well known and widely used to quantify bed level changes on the foreshore. Using PTs is a new method introduced by Baldock and et al. (2005) but testing the method by comparing with other data on bed level changes collected simultaneously with the PTs has not been performed. In this study a comparison between bed elevation changes obtained through rod measurements and PTs shows perfect agreement in the upper and mid swash over a period of several hours. In the lower swash minor disagreement $(1 \mathrm{~cm})$ occurs. This is because the accuracy of the two methods becomes less when measuring in the lower swash and inner surf zone. In the lower swash and inner surf zone the upper part of the bed becomes fluidized and more loosely packed and as the swash zone translates across the foreshore on the rising tide, the bed state at a given rod will change from firmly to more loosely packed, as it enters the lower swash zone. Therefore, rod measurements tend to underestimate the relative bed level because the measuring device used to measure the distance from the top of the rod to the bed, may sink slightly into the bed. Bed level changes upon entering and during lower swash zone conditions may therefore be overestimated. The relative bed level found using the PT output signal might be overestimated because the bed is less frequently exposed, as the backwash often has not completed before the next uprush arrives (swash-swash interaction). Thus, the water level could be misinterpreted as bed level. Combining the two methods in the lower swash seems to give a fair estimate of the actual bed level changes. The accuracy of the bed level measurements in the lower swash is less than in the rest of the swash zone but as the accuracy is in the order of $\pm 1 \mathrm{~cm}$ the use of rods and PTs still gives good results on bed levels in the lower swash.

By using PTs it is possible to quantify bed level changes at inter-swash level in the order of millimetres and to identify how much accretion or erosion a specific swash event accounts for. Similar to Brocchini and Baldock (2008), Blekinsopp et al. (2009) and Masselink et al. (2009) large bed level changes caused by a single swash event have been observed using the PTs. It appears that choosing the right window size to determine the bed levels highly influences the results on bed level change. In the mid and lower swash, where wave-swash interaction is prevailing, bed level changes tend to be overestimated if the window size is too narrow, and it is therefore very important to manually inspect 
large bed elevation changes found using an automated method before any firm conclusions can be made on these events.

The characteristics of the swash throughout the swash zone can be identified by displaying the water levels derived from the PTs. It appears that the swash is quite different in the upper, mid and lower swash, which is probably due to the different degrees of wave-swash interaction. As other studies have concluded (e.g. Aagaard and Hughes, 2006; Weir et al., 2006; Baldock, 2009, Jensen et al., 2009, Masselink et al., 2009) this indicates that the hydrodynamics vary throughout the swash zone and explain why modelling swash zone sediment transport is very difficult.

Bores and the maximum sediment concentrations at the bore front have successfully been identified from data on water levels at the surf-swash boundary using a bore front steepness criterion. To quantify the amount of sediment suspended from bore collapse at the inner surf-swash boundary it is necessary to identify the collapsing bores. This is not possible from one water level time series alone. Using the method presented here, inner surf bores can be identified and tracked from PTs closely spaced and synchronised. If the height of a given bore decreases significantly from one PT to the next PT (e.g. spaced by $1 \mathrm{~m}$ ) it is likely that bore collapse has occurred. Another option is to synchronise data with video recordings. Most bore collapse events probably coincide with high sediment concentration events, and these events could therefore be used as indicators of where to find the bore collapse events.

The use of PTs in the swash zone has proven very useful as accurate bed level changes and water levels are obtained at the same time. The high resolution makes it possible to describe bed elevation changes and water levels at inter-swash level to hours. Furthermore, large detail on bed level development, e.g. bed forms, is given by the high resolution. Sudden erosion or accretion can be due to the migration of ripples or berms (e.g. Jensen et al., 2009), but features like ripples can not be tracked using rods measurements. The method of using self-logging PTs is a very flexible method because without cables it is possible to move the transducers with the swash zone as it translates across the foreshore with the rising or falling tide. In this way, problems like those described by Masselink et al. (2009) where the run-up limit sometimes extended landward of the instrument rig and the full effect of the swash on bed level changes therefore could not be obtained, is overcome. Furthermore, the transducers are very robust and the deployment beneath bed level offers some protection from the high energy generated when bore collapse occurs and from the energy generated at the turbulent bore front.

\section{CONCLUSION}

A method, in which buried self-logging pressure transducers in the swash zone are used to measure inter-swash bed level changes over a timeframes of hours, has been tested against bed level changes obtained from rod measurements. It is concluded that the deployment of self-logging pressure transducers in the swash zone is an accurate, easy and flexible method to obtain highly detailed data on water levels and bed elevations. Water levels derived from the pressure transducers show that swash zone characteristics varies from the upper to lower swash. Individual bores and the suspended sediment load entrained at the bore front have been successfully identified at the surf-swash boundary. The method presented to select bores can be used to track bores at the surf-swash boundary and identify bore collapse and the corresponding suspended sediment load. Coupled with the highly detailed data on bed level changes and water levels in the swash zone obtained using pressure transducers, provides a method to estimate the sediment advection from collapsing bores.

\section{ACKNOWLEDGEMENTS}

This work was funded by the Danish Natural Sciences Research Council (FNU) through grant number 272-05-0415. Stine G. Jensen was funded by the Faculty of Science, University of Copenhagen through a PhD scholarship. We thank the Department of Forestry and Nature for permission to work at Vejers. Bo Dalbjerg Jensen (U. Copenhagen) and Dave Mitchell (U. Sydney) assisted with the installation of the electronics.

\section{REFERENCES}

Aagaard, T., Hughes, M. G., 2006. Sediment suspension and turbulence in the swash zone of dissipative beaches. Mar. Geol. 228, 117-135.

Baldock, T.E., Barnes, M.P., Hughes, M.G., 2005. Field observations of instantaneous cross-shore free surface profiles and flow depths in the swash zone. Proc. Coastal Dynamics 2005, Barcelona, ASCE. 
Baldock, T. E., 2009. Discussion of "Measurements of wave-by-wave bed-levels in the swash zone" by Ian L. Turner, Paul E. Russell, Tony Butt, [Coastal Eng. 55 (2008) 1237-1242]. Coastal Engineering 56, 380-381.

Blekinsopp, C. E., Turner, I. L., Masselink, G., Russell, P. E., 2009. Field measurements of net sediment flux from individual swashes on a sandy beach. Proc. Coastal Dynamics 2009, Tokyo. Paper No. 27.

Brocchini, M, Baldock, T., 2008. Recent advances in modelling swash zone dynamics: influence of surf-swash interaction on nearshore hydrodynamics and morphodynamics. Reviews of Geophysics 46, RG3003, 21pp.

Butt, T., Russell, P., 2000. Hydrodynamics and Cross-Shore Sediment Transport in the Swash-Zone of Natural Beaches: A Review. Journal of Coastal Research, 16(2), pp. 255-268.

Hughes, M., Masselink, G., Brander, R., 1997a. Flow velocity and sediment transport in the swash zone of a steep beach. Marine Geology 138, 91-103.

Hughes, M. G., Masselink, G., Hanslow, D., Mitchell, D., 1997b. Toward a better understanding of swash zone of swash zone sediment transport. Proc. Coastal Dynamics '97. ASCE, pp. 804-813.

Hughes, M. G., Aagaard, T., Baldock, T. E., 2007. Suspended sediment in the swash zone: heuristic analysis of spatial and temporal variations on concentration. Journal of Coastal Research, 23, pp. $1345-1354$.

Hughes, M., Moseley, A. S., 2007. Hydrokinematic regions within the swash zone. Continental Shelf Research 27, 2000-2013.

Jensen, S. G., Aagaard, T., Baldock, T. E., Kroon, A., Hughes, M., 2009. Berm formation and dynamics on a gently sloping beach; the effect of water level and swash overtopping. Earth Surf. Process. Landforms 34, 1533-1546.

KDI, 2001. The Sediment Budget along the West Coast of Jutland. Report, Danish Coastal Authority: Lemvig; 54pp. (In Danish).

Masselink, G., Hughes, M., 1998. Field investigation of sediment transport in the swash zone. Continental Shelf Research 18, 1179-1199.

Masselink, G., Russell, P., Turner, I., Blekinsopp, C., 2009. Net sediment transport and morphological change in the swash zone of a high-energy sandy beach from swash event to tidal cycle time scales. Marine Geology 267, 18-35.

Power, H. E., Hughes, M. G., Aagaard, T., Baldock, T. E., 2010. Nearshore wave height variation in unsaturated surf. Journal of Geophysical Research, Vol 115, C08030, 15pp.

Pritchard, D., Hogg, A. J., 2005. On the transport of suspended sediment by a swash event on a plane beach. Coastal Engineering 52, 1-23.

Puleo, J. A., Beach, R. A., Holman, R. A., Allen, J. S., 2000. Swash zone sediment suspension and transport and the importance of bore-generated turbulence. Journal of Geophysical Research, Vol. 105, No. C7, 17021-17044.

Weir, F. M., Hughes, M. G., Baldock, T. E., 2006. Beach face and berm morphodynamics fronting a coastal lagoon. Geomorphology, 82, 331-346.

Wright L. D., Short A. D. 1984. Morphodynamic variability of surf zones and beaches; a synthesis. Marine Geology 56: 93-118. 